\title{
HIV: Biology to Treatment
}

\author{
Ashish Swarup Verma, Vipin Kumar, Malay Kumar Saha, \\ Shanta Dutta, and Anchal Singh
}

\begin{abstract}
AIDS is one of the most dreaded diseases of the twenty-first century caused by human immunodeficiency virus (HIV). Recently, there are reports which show decline in new infections due to better access to anti-retroviral drugs. Still on a daily basis, 2356 new HIV infections are being reported globally. New treatments and anti-HIV drugs are being continuously developed with the aim to control and cure AIDS. The anti-HIV drugs that are in use usually target HIV entry and replication inside the host cells. However, these drugs are only partially effective in slowing the rate of HIV replication. Nevertheless, the virus manages to replicate at much slower rates even when anti-retroviral treatment is ongoing. The HIV seropositives who are on anti-retroviral treatment for long periods of time are now developing different kinds of other complications including neuroAIDS. The latest development in HIV therapy is a novel kind of bone marrow transplantation from donors who have a homozygous mutation in CCR5 gene.
\end{abstract}

\section{Keywords}

AIDS $\cdot$ ARD $\cdot$ ART $\cdot$ HAART $\cdot$ HIV $\cdot$ NeuroAIDS

\footnotetext{
A. S. Verma

Jadavpur University, Kolkata, WB, India

V. Kumar · A. Singh $(\bowtie)$

Department of Biochemistry, Institute of Science, Banaras Hindu University,

Varanasi, UP, India
}

M. K. Saha $\cdot$ S. Dutta

National Institute of Cholera and Enteric Diseases (NICED), Kolkata, WB, India 


\section{Abbreviations}

$\begin{array}{ll}\text { AIDS } & \text { Acquired immunodeficiency syndrome } \\ \text { AML } & \text { Acute myeloid leukemia } \\ \text { ARD } & \text { Anti-retroviral drug/s } \\ \text { ART } & \text { Anti-retroviral treatment/s } \\ \text { BBB } & \text { Blood-brain barrier } \\ \text { CNS } & \text { Central nervous system } \\ \text { Env } & \text { Envelope } \\ \text { Gag } & \text { Group-specific antigen } \\ \text { HIV } & \text { Human immunodeficiency virus } \\ \text { InI } & \text { Integrase inhibitors } \\ \text { LTR } & \text { Long terminal repeat/s } \\ \text { Nef } & \text { Negative factor } \\ \text { NNRTI } & \text { Non-nucleoside reverse transcriptase inhibitor/s } \\ \text { NRTI } & \text { Nucleoside reverse transcriptase inhibitor/s } \\ \text { NtRTI } & \text { Nucleotide reverse transcriptase inhibitor/s } \\ \text { PDI } & \text { Protein disulfide isomerase } \\ \text { PI } & \text { Protease inhibitor/s } \\ \text { PNS } & \text { Peripheral nervous system } \\ \text { Pol } & \text { Polymerase } \\ \text { Rev } & \text { Regulator of viral expression } \\ \text { Tat } & \text { Transactivator of transcription } \\ \text { Vif } & \text { Viral infectivity factor } \\ \text { Vpr } & \text { Viral protein R } \\ \text { Vpu } & \text { Viral protein U } \\ & \end{array}$

\subsection{Introduction}

A possibility of life without having infections or suffering from infection/s is just beyond imagination in any natural conditions or scenario. Infections affect us irrespective of our habit and habitat. No matter where we live? How we live? No matter in what hygienic conditions we live!!! All of us have to live and to face infections numerous times throughout our life.

If we go through the historical records, history of infections is prehistorical in existence. Infections and diseases caused by infective agents have been recorded even in ancient times, too. Biblical records clearly mentioned about the havoc caused by plague. Although descriptions of infections and infectious diseases in older times were not well documented, infections at the present time have been well documented and recorded. Human life always remains vulnerable to infections throughout his/her life irrespective of age, sex, race, or any other variable that we can imagine. One should not be surprised to know that human life can be infected even before someone is born. The infections before birth are commonly called as 
prenatal infections, e.g., infection of herpes simplex virus (HSV) is one of the most common prenatally reported infections. We can easily conclude a fact that infections and life are very closely associated with each other. During the last century, medical sciences have been credited with two major discoveries, i.e., vaccines and antibiotics. Vaccines and antibiotics brought dramatic changes reducing the morbidity as well as preventing the mortality caused by some of these infections. The success to control infections with the use of vaccines and antibiotics is so tremendous that these discoveries almost lead us to believe that we are wining the war against microbes/infections. Knowing the current status as well as realizing the current scenario about infection and infectious diseases can we claim if the abovementioned statement still holds the water!!! A sudden eruption and reporting of new and more fatal diseases like SARS, HIV, Ebola, swine flu, etc., to name a few if not all. Some of these diseases remained confined within certain geographical boundaries, while some were presented with their sporadic presence. HIV infections have been reported as a new type of infection. During the last quarter of the twentieth century, HIV infections are indiscriminate to age, sex, and race, and soon it was realized that HIV infections do not even know any geographical boundaries. HIV does not show any sporadic presence or any seasonal dependency. As a matter of fact, HIV infections raised eyebrows of policy makers due to the global presence of HIV which soon started taking the shape of a global epidemic. HIV being a global epidemic has received unprecedented attention from all quarters of life may it be the government or nongovernment organizations. HIV even attracted attention of various religious groups due to the homosexual behavior of the initial HIV patients reported with HIV infections. This mysterious infection due to its fatal nature and quantum of infected people has received more than warranted attention from scientists, clinicians, policy makers, media, etc. But what were the reasons behind such a public attention or outcry for HIV infections? Still there are no conclusive answers to it, but there are certain theories which prevail behind it.

\subsection{History}

History of HIV and AIDS epidemic begins with illness, fear and death, which was faced by the world due to a new and unknown virus.

The history of HIV and AIDS goes back to the year 1981. It was the year 1981, when the initial cases of HIV/AIDS were reported. Ideally these cases were unknowingly "known" cases of HIV and AIDS. These initial cases were reported with a rare lung infection. These patients were suffering from Pneumocystis carinii pneumonia (PCP) (Gottlieb et al. 1981). PCP is known as an opportunistic infection. Only severely immune compromised host or patients get affected by PCP which is considered as a fatal disease. In the year 1981, the term AIDS was not even coined, so these patients were diagnosed with PCP not as patients of HIV/AIDS. Later it was recognized that these PCP patients were actually patients of AIDS. This is the reason these cases can be considered as unknowingly "known" patients of AIDS. 
The characteristic feature of AIDS is almost a devastated immune system with the assurance of death at the end, and the onset of death in case of HIV/AIDS patient is simply a matter of time. It will not be wrong to say AIDS is the ultimate and final chapter of life of a HIV patient. Clinically AIDS is defined as high viral load and low CD4 ${ }^{+} \mathrm{T}$-cell counts $(<200$ cell/ml of blood) along with the presence of AIDSdefining diseases like HAD, HIV wasting syndrome, AIDS-defining cancers like Kaposi's Sarcoma, etc. (www.who.int). It is commonly believed that HIV is a single virus, though as a matter of fact there are two types of HIV, and those two different types of HIV are HIV-1 and HIV-2. Out of these two different types of HIV, HIV-1 is more prevalent with global presence and with fatal consequences, while in contrast HIV-2 is less prevalent and causes a slow progressing disease. This chapter is focused on HIV-1 and the term HIV in the chapter implies HIV-1.

The first report about PCP among five gay men was published by Dr. Michael S. Gottlieb and his group in 1981 issue of MMWR. MMWR is a publication from Centers for Disease Control and Prevention (CDC), Atlanta, USA. The rationale question is why these patients were classified as PCP patients rather than AIDS patients. The answer is that, at that time the term AIDS was neither a part of general vocabulary nor even a part of medical dictionary. Nonexistence of the AIDS term is the major reason for the existence of this discrepancy in literature. The most fascinating fact about the saga of AIDS is that the world community is indebted to the alertness of a technician Ms. Sandra Ford at CDC where she was responsible for dispensing a rare and controlled drug, pentamidine. She had seen an unusual increase in numbers of requests to dispense this very rare medicine. Due to her alertness, Ms. Ford brought this matter to the attention of her bosses at CDC. This fact was verified in her interview to a famous US magazine Newsweek. Her statement is like this:

A doctor was treating a gay man in his 20's who had pneumonia, 2 weeks later he (doctor) called to ask for a refill of a rare drug that I handled. This was unusual nobody ever asked for a refill. Patients usually were cured in one 10-days treatment or they died. By Sandra Ford

Realizing the significance of this new observation, CDC USA formed a "Task Force on Kaposi's Sarcoma and Opportunistic Infections (KSOI)." At this point of time, very limited information was available about this new and deadly disease. The major concerns were about the mode of transmission for this new and fatal disease. Since no official name existed for this new disease, this new disease was initially identified as lymphadenopathy or KSOI.

Majority of cases for this new disease were initially reported only among homosexual gay men so it is obvious that various new names were adopted in literature for reporting this new disease. These new names somehow adopted the gay cultivate/word to evolve new names for the disease. Some of the common names that were used in literature for this new disease were gay compromise syndrome (GCS), gay-related immune deficiency (GRID), acquired immunodeficiency disease (AID), community-acquired immune dysfunction (CAID), and gay cancer. The role of gay lifestyle started giving strength to this new and fatal disease though very soon this assumption turned out to be wrong because by late 1982, a 20-month-old child was also reported with this new and fatal disease. As per the clinical history, the child 
had received multiple blood transfusions. Later it was realized that the cause of this disease in this 20-month-old child could be the blood, or transmission of new infection could be due to the transfusion of infected blood.

This case of 20-month-old child raised an alarm for the need of safe blood supply from blood banks. Soon cases for this new and fatal disease were getting reported from all walks of life. These observations have been helpful to delink this myth about the connection of new and fatal disease with unique lifestyle followed by gay men. Therefore, lifestyle-related name used for this disease has lost their relevance. To avoid further confusions among clinicians, there was a dire need to coin a new term and appropriate name for this new disease. To address this overgrowing problem, a meeting was convened on July 24, 1982, in Washington, and in this meeting AIDS was coined as a new name for this new and fatal disease.

Since the formation of KSOI and close monitoring of the disease status, cases were reported from all corners of the USA. Soon detection of this new disease in Haitian hemophiliacs was one of the reasons to believe that the disease might have originated from Haiti. By the end of 1982, AIDS cases were reported from various European countries as well as from the countries of African continents. The quantum of this disease can be realized from the spread of this disease with a fact that by year 1983, 3064 cases of AIDS were reported out of which 1292 had already died (https://www.avert.org/professionals/history-hiv-aids/overview). These numbers about AIDS patients had been a motivating factor to realize the sense of urgency regarding this disease among various sections of the society. The concerns and seriousness related to the disease compelled for an urgent need to find out the causative agent as well as effective treatment strategies against the disease.

Initially researches on this unknown disease were started in France and the USA. The causative agent for this new disease was reported by Luc Montagnier's group who was working at Pasteur Institute, Paris, France. In 1983, Montagnier's group named this virus as lympadenopathy-associated virus (LAV). Montagnier's work was published in May 20, 1983, issue of Science. This first publication was authored by 12 investigators (Barre-Sinousi et al. 1983). The contribution of Montagnier's work was finally recognized by awarding him the Nobel Prize in Physiology and Medicine in 2008. Unfortunately, Montagnier's publication did not attract the required attention from scientific community for almost a year till the findings of another group from the USA were published in the same journal. In May 4, 1984, issue of Science, findings from Robert Gallo's group at National Cancer Institute (NCI), Bethesda, USA, were published (G). This new article was authored by 13 investigators of Gallo's group wherein they have given the name of this virus as human T-cell lymphotropic virus. Later it was decided that both of them (Montagnier and Gallo) should be equally credited for the discovery of this new organism.

In 1985, the first case of HIV transmission from breast milk to infant was reported. In the meantime HTLV-III and LAV names started creating confusion in literature about the name as well as nomenclature for the same virus. Therefore, in 1986, the International Committee on Taxonomy of Viruses decided to drop both the names, i.e., LAV and HTLV-III. The new name for this virus was given as human immunodeficiency virus (HIV). This new name has been in use since the HIV term is very pertinent with the symptoms of the disease caused by HIV. 
Year 1987 has been important in the history of HIV and AIDS because of two important developments: (1) the US Food and Drug Administration (USFDA) has approved Azidothymidine (Zidovudine) as the first drug to treat HIV infection, and (2) the World Health Organization (WHO) also launched the Global Programme on AIDS to raise awareness, to generate evidence-based policies, and to provide technical and financial support to countries affected by this disease (www.who.int). WHO also declared December 1st as World AIDS Day in 1991. By the year 1996 the United Nations Organization (UNO) had established a Joint United Nations Programme (UNAIDS) to advocate for global action on HIV/AIDS epidemic and to coordinate the response across the world. The annual report of UNAIDS is considered as one of the most authentic reports on the global status of HIV and AIDS. As per UNAIDS report of 2018, there is a significant decline of new infections (especially among children of age less than 15 years) and deaths due to AIDS, while access to ART and funds to deal with HIV/AIDS epidemics has seen an increasing trend (http://www.unaids.org/en/resources/documents/2018/unaids-data-2018).

\subsection{HIV Disease Burden: An Improvement}

Since the establishment of office of UNAIDS by United Nations, UNAIDS publishes annual reports about the status of HIV and AIDS at global level. Annual reports published by UNAIDS are considered as the most accurate and authentic document about the epidemiology of HIV and AIDS. The most recent report of UNAIDS was published in July 2018 (http://www.unaids.org/en/resources/documents/2018/unaids-data-2018). This report has provided details about the global status of HIV and AIDS as of the year 2017 (Table 7.1). There is no doubt that the

Table 7.1 HIV epidemiology: a comparison between 2010 \& 2017

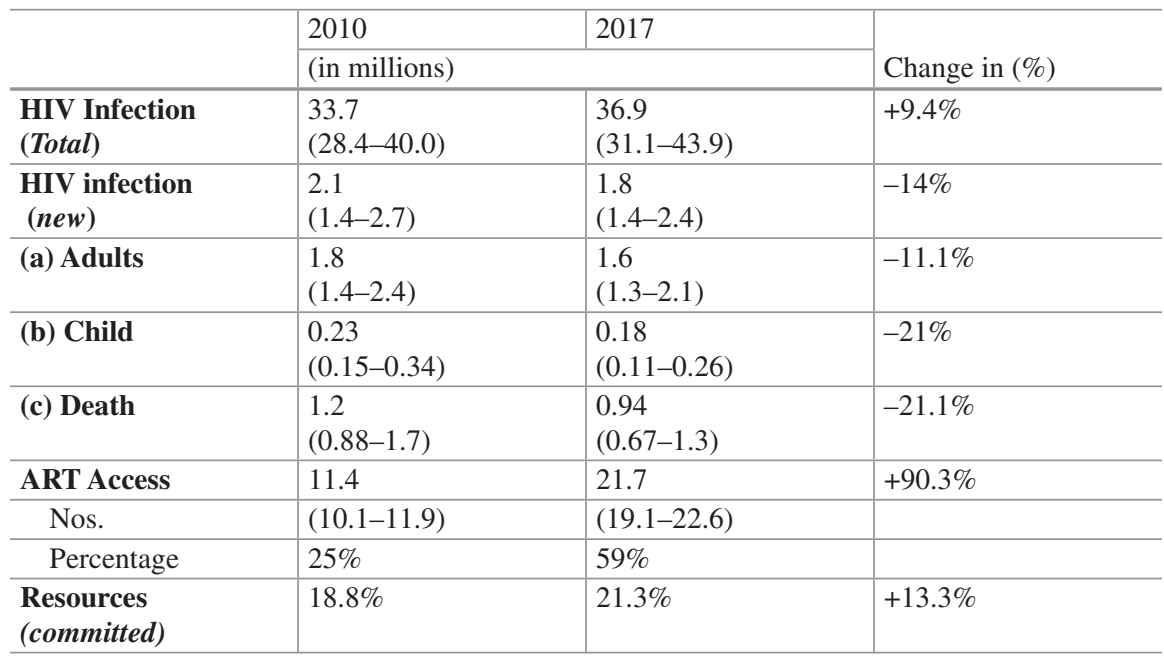

Values present in 3rd column is representing the percent increase or decrease in the year 2017 compared to year 2010. Value present in parenthesis represents the range 
data presented in the report is very encouraging with regard to the current status of HIV and AIDS. UNAIDS report is quite comprehensive on various aspects related to HIV and AIDS like new infections, access to anti-retroviral drugs, deaths due to AIDS and AIDS-related diseases, vertical transmission of HIV, and even the financial resources available or committed to deal with HIV and AIDS epidemic (UNAIDS Report 2012).

As per these new estimates presented in UNAIDS report 2017, 36.9 million (a range of 31.1-43.9) people are living with HIV infections, which is $\sim 9.4 \%$ higher compared to the people living with HIV in 2010. An increase in total number of HIV-infected people is due to two confounding factors, i.e., (1) new HIV infection and (2) now HIV-infected persons who are living longer due to improved ART as well as a significant decline in AIDS-related deaths. Out of the 36.9 million infected people, adults account for 35.1 million out of which men are 18.2 million and women are 16.8 million, while children below the age of 15 years are 1.8 millions. The most encouraging fact about HIV infections is consistent decline in new infections since the first report. In 2017, new infections reported are 1.8 million (in the range of 1.4-2.4 million) which is $~ 14 \%$ decline of new HIV infections in the last 7 years, i.e., 2010. Out of these 1.8 million new HIV infections, 1.6 million cases are reported among adults, while only 0.18 million new HIV infections are reported from children below the age of 15 years. Decline of new infections among children is $21 \%$ compared to adults where decline of new infections is only $11.1 \%$. This new observation is certainly a very good sign toward a better control over spread of new HIV infections in the present time. A significant decline in vertical transmission of HIV infection must have played a crucial role for this decline among children. Similarly deaths related to AIDS have also been reduced to 0.94 million compared to 1.2 million in 2010 which amounts to $21 \%$ decline in death due to AIDS and AIDS-related diseases in 2017 compared to 2010. The most satisfying part of this data is the better access for ART treatment to HIV-infected patients. At present around 21.4 million people with HIV infection have access to ART compared to only 11.4 million in 2010. This data suggests that in the last 7 years, access to ART has almost doubled and in the near future access to ART is expected to improve further globally. Since 2010, there is a consistent increase in the financial resources available to deal with HIV epidemic. By the end of 2017, more than 21 billion US dollars were available to deal with HIV epidemic.

As per the latest data available to us, 4931 individuals get new HIV infections, while $\sim 2575$ HIV infected people die every day. So on a daily basis, there is an addition of $2356 \mathrm{HIV}$-infected persons to the already existing pool of HIV-infected people. If we do the math, it means that on annual basis, we are adding more than 0.8 million HIV-infected people to the already existing pool of HIV-infected individuals, which is almost more than the population of majority of capital cities of European nation, barring few large cities; the majority of HIV seropositives and AIDS patients live in underdeveloped nations as well as developing nations. Such a high number of HIV seropositives in these nations is indicative of multiple factors, viz., poor implementation of surveillance program, poor health care and health-care system, poor living conditions, lack of resources, social factors, etc. There is no doubt that more serious and concerted efforts are warranted at local, national, and 
international levels to bring a better control of HIV epidemic especially in underdeveloped and developing nations.

A closer look of UNAIDS 2018 report suggests the following important issues:

1. A decline in new HIV infections.

2. Increase in total number of people living with HIV.

3. A decline in AIDS-related deaths.

4. More than $75 \%$ people living with HIV know their status about HIV infections.

5. $~ 59 \%$ of people with HIV infection have access to ART.

6. $\sim 47 \%$ decline in new HIV infections compared to 1996.

7. $\sim 51 \%$ decline in AIDS-related deaths since 2004.

8. $>77.3 \%$ millions have been infected with HIV since the start of HIV epidemic.

9. >35.4 million have already died with AIDS-related illnesses since the start of HIV and AIDS epidemic.

10. $>2 / 3(\sim 65 \%)$ of total HIV infections are reported only from the countries of African continent.

11. Least number of cases of HIV and AIDS are reported from the Pacific.

\subsection{HIV: Molecular Biology}

HIV is a virus which belongs to Retroviridae family and its genus is Lentivirus. HIV is a small-size virus which is roughly spherical in shape. The diameter of HIV virion is $\sim 120 \mathrm{~nm}$. The characteristic feature of Retroviridae family is its genome. The genome of retroviruses is RNA not the DNA. HIV contains a single-stranded RNA (ssRNA), and this ssRNA is a positive sense RNA which acts as genome. This ssRNA passes the genetic information to the next generation during replication. Presence of a unique enzyme, i.e., reverse transcriptase (RT), is a must for retroviruses. The main role of RT is to reverse-transcribe RNA to DNA, and this newly synthesized DNA from RNA is called as "pro-viral DNA." The genome size of HIV is $\sim 9.8 \mathrm{~kb}$. HIV genome consists of nine genes in total which are flanked by long terminal repeats (LTRs) on either side of the genome (Fig. 7.1). These 9 genes of HIV produce 15 different viral proteins during replication of HIV (Frankel and Young 1998). The main role of LTR is to integrate pro-viral DNA to the host cell DNA. Synthesis of new virion starts from LTR because transcription factors from host cells bind to LTR of viral genome for the integration of pro-viral DNA to the genome of host cell. These 15 viral proteins are divided into 3 categories (1) structural proteins, (2) regulatory proteins, and (3) accessory proteins. Gag, Pol, and Env are structural proteins; Tat and Rev are regulatory proteins; and Nef, Vif, Vpr, and Vpu act as accessory proteins of HIV. 


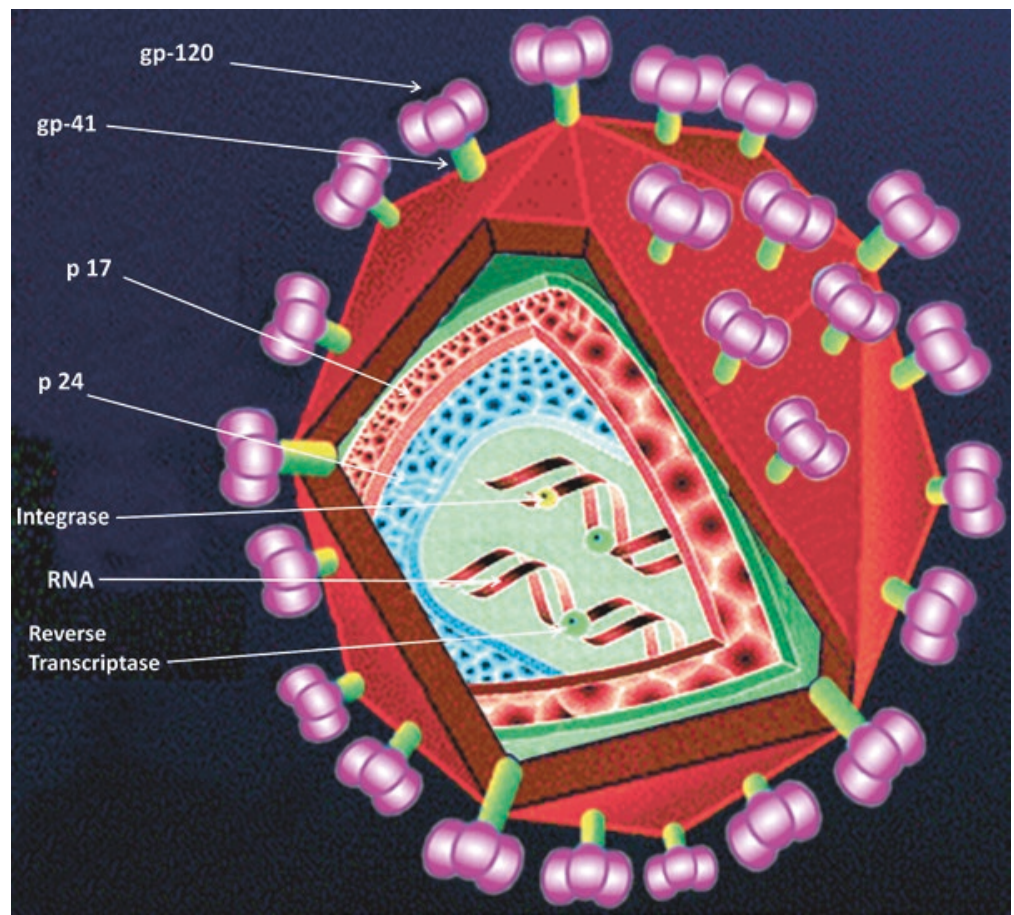

Fig. 7.1 HIV genome

Schematic representation of HIV genome. This size of HIV genome is $9.8 \mathrm{kB}$. HIV genome consists of nine different genes. HIV genes are flanked by long-term repeats (LTR) on either side of full genome. During HIV replication, totally 9 genes of HIV produces 15 different proteins. env envelope, gag group specific antigen, LTR long terminal repeats, nef negative factor, pol polymerase, rev regulator of viral expression, tat transactivator of transcription, vif viral infectivity factor, $v p r$ viral protein $\mathrm{R}, v p u$ viral protein $\mathrm{U}$

\subsubsection{Envelop (Env)}

The term Env has been developed from the term "envelope." The size of env gene is 2570 nucleotides which are located between 5571 and 8341 . The size of env precursor protein is $160 \mathrm{kDa}$. Env is a glycoprotein and synthesized as polyprotein precursor. The precursor of Env protein is known as gp160. gp160 is processed or cleaved by cellular proteases which results in the production of two different glycoproteins: (i) gp120 and (2) gp41. Gp120 acts as surface glycoprotein, while gp41 acts as a transmembrane glycoprotein. gp120 interacts with CD4 receptor, while gp41 interacts with chemokine receptors. gp41 consists of three domains: (1) ectodomain, which is responsible for the fusion, (2) transmembrane domain which acts as an anchor, and (3) cytoplasmic tail. The inding of gp120 to its receptors induces conformational changes in gp41. Conformational changes lead to the formation of gp120/gp41 glycoprotein complex which result in the fusion of virus to the host cell. 


\subsubsection{Group-Specific Antigen (Gag)}

The Gag word has been derived from "group-specific antigen." The size of gag gene is 1502 nucleotides and is located between 336 and 1838 nucleotides. Gag gene produces a protein of $55 \mathrm{kDA}$ which is comprised of 550AA. Gag gene encodes for Pr55gag, which acts as a polypeptide precursor. The main role of this polyprotein precursor is to complete the viral assembly at the end of viral replication cycle. Pr55gag cleaves into different proteins, viz., p6, p7, p17, and p24 as well, as two spacer proteins, i.e., p2 and p1. Out of these four proteins, p17 is a matrix protein (MA), p24 is a capsid protein (CA), p7 is a nuclear capsid (NA), and p6 is known as Vpr binding proteins. N-terminal of MA is mainly responsible for targeting and binding to plasma membrane.

\subsubsection{Negative Factor (Nef)}

The Nef term is coined from "negative factor." The size of Nef gene is 620 nucleotides which is present between 8343 and 8963. Nef is an accessory protein with molecular weight of $27 \mathrm{kDa}$ which is comprised of 206AA. Nef is expressed during early stages of viral replication in host cells. Nef downregulates cell receptors like CD4, CD8, CXCR4, CCR5, etc. Due to the downregulation of receptors for HIV infection, the role of nef is important for HIV pathogenesis. The in vitro studies of nef suggest the following main functions of nef: (1) perturbs endocytosis, (2) modulates signal transduction pathway in HIV-infected cells, (3) supports enhancement of viral infectivity, and (4) supports fusion of HIV to permissive target cells. Nef is also considered to play a significant role in altering CNS functions in HIV-infected individuals. A higher level of nef has been reported to affect the growth of astrocytes. Nef has been reported to alter electrophysiology of neurons.

\subsubsection{Polymerase (Pol)}

The Pol name has been coined from the word "polymerase." Pol gene consists of 2803 nucleotides, and the location of pol gene is from 1839 to 4642 nucleotides. The molecular weight of pol protein is $112 \mathrm{kDa}$ and it comprises of $935 \mathrm{AA}$. Pol protein is initially synthesized as a large polyprotein precursor, i.e., Pr160-Gag-Pol. Due to cleavage of Pr160-Gag-Pol by viral protease, it produces viral proteases (PR or p10), reverse transcriptase (RT or p64), and integrase (IN or p32). Out of these proteins, RT is a heterodimer of two subunits, i.e., $64 \mathrm{kDa}(\mathrm{p} 64)$ and $51 \mathrm{kDa}(\mathrm{p} 51)$. These two subunits are derived from the same region of Pr160-Gag-Pol precursor protein. Integrase is a single polypeptide with molecular mass of $32 \mathrm{kDa}$. Integrase promotes the integration of pro-viral DNA (linear but double-stranded) to the genome of host cell. Integration is absolutely a necessary step for viral replication. It has been reported that integrase mutant viruses fail to spread HIV infections. 


\subsubsection{Regulator of Expression of Viral Proteins (Rev)}

Rev is coined from the word "regulator of expression of viral proteins." Rev protein is encoded by two exons. Rev gene comprises 75 to 274 nucleotide sequences. The rev gene is located between 5516-5591 and 7925-8199. The collective length of Rev gene is 349 nucleotides. Rev works as a regulatory protein and is important for the regulation of viral replication. The molecular mass of Rev protein is $191 \mathrm{kDa}$ with 116AA in total. Rev downregulates splicing of viral RNA post-transcriptionally. Rev contains two domains: (1) arginine-rich domain and (2) leucine-rich domain.

\subsubsection{Transactivator of Transcription (Tat)}

The term tat is coined from "transactivator of transcription." Tat gene comprises 259 (214 and 45 nucleotides) nucleotides and location of tat gene is between 5377-5591 and 7925-7970. Tat is 86-110 AA-long protein with molecular mass of $16 \mathrm{kDa}$. Tat is a nonstructural protein which is a product of two exons. It has three main domains: (1) activation domain, (2) basic RNA-binding domain, and (3) overlapping nuclear localization signal. Secreted tat can be taken up by neighboring cells; therefore tat affects both infected and the non-infected cells. Tat has been shown to affect HIVinfected individuals with known CNS pathology. Tat can induce apoptosis in neurons via oxidative stress pathway.

\subsubsection{Viral Infectivity Factor (Vif)}

The term Vif is coined from the word "viral infectivity factor." Vif gene has conserved sequences among lentiviruses. The size of Vif gene is 578 nucleotides, and its location is between 4537 and 5165 . The molecular mass of Vif protein is $23 \mathrm{kDa}$ which is comprised of 192 AA. Vif is expressed during the late stage of viral replication and is present in the cytoplasm of infected cells. Vif inhibits the premature processing of p55Gag in cell cytoplasm. The main role of Vif is to produce competent virions.

\subsubsection{Viral Protein $\mathbf{R}($ Vpr)}

The term Vpr is coined from "viral protein R." The size of Vpr gene is 296 nucleotides which is localized between 5105 and 5396. Vpr is an accessory protein of HIV and is not essential for HIV replication. The molecular mass of $\mathrm{Vpr}$ is $14 / 15 \mathrm{kDa}$, and it has 96AA arranged in three domains. Vpr is known to have numerous biological functions like transcription of viral genome, apoptosis, etc. Since Vpr can breach the cell membrane, extracellular Vpr can enter in non-infected cells too (Verma et al. 2012). 


\subsubsection{Viral Protein U (Vpu)}

The term Vpu is coined from "viral protein U." The size of Vpu gene is 248 nucleotides, and location of Vpu gene in HIV genome is between 5608 and 5856. The molecular mass of $\mathrm{Vpu}$ is $16 \mathrm{kDa}$ accounting for 62AA. $\mathrm{Vpu}$ is a type 1 integral membrane phosphoprotein. Vpu is an accessory protein so it is not essential for HIV replication. Vpu gets expressed during HIV replication. Vpu cannot be detected in virus itself because Vpu does not get packed into viral particle. Vpu consists of two domains: (1) N-terminal and (2) C-terminal. The main function of Vpu is to enhance the release of viral particles and degradation of CD4.

\subsubsection{Long Terminal Repeats (LTRs)}

LTR term is derived from "long terminal repeats." LTR is present on either side of viral genome. LTR serves as the initiation site for the transcription of viral genome. It harbors cis-acting elements which are needed for RNA synthesis. LTR contains three regions: (1) U3, (2) R, and (3) U5. U3 is known as "unique 3'end," $\mathrm{R}$ is known as "repeat," and U5 is known as "unique 5'end." Various elements present in U3 support the direct binding of RNA polymerase II (pol II) to DNA templates. Newly synthesized viral RNA falls under three main categories: (1) unspliced RNA which acts as precursor for Gag and gag-pol polyprotein; (2) partially spliced mRNA ( $\sim \mathrm{kb}$ ) which encodes for Env, Vif, Vpu, and Vpr proteins; and (3) small but multiple spliced mRNAs (1.7-2.0 kb) which encode for Rev, Tat, and Nef. Normally the basal transcriptional activity of LTR is very low, but presence of Tat enhances the transcription rate to many folds.

\subsection{HIV Replication}

HIV is a virus so it can be easily considered as a bag of nucleoprotein complex. Like any other virus, HIV is also a dead (or non-living) complex of nucleoproteins when HIV is out of its host. Being a virus, HIV has a specific host, i.e., humans. Even in humans there is a specific target cell for the infection of HIV. The main target for HIV infectivity is T-helper cells or $\mathrm{CD}^{+}{ }^{+} \mathrm{T}$-cells. A significant decline of $\mathrm{CD}^{+}$cell count is the hallmark for HIV infection. HIV infections are fatal in nature with high morbidity. Even though initial cases of HIV infections were reported in 1981, the term HIV was coined only in the year 1987. Infections with such fatal consequences necessitated the need for development of drugs to find a cure for HIV infections. For the development of new drugs for any infectious agents like HIV, it is of utmost importance to know the drug targets. For the identification of drug targets, it is very useful to have a better understanding about different steps or stages of viral life cycle or viral replication. Therefore serious efforts have been made to delineate the various steps of HIV replication in details which can be used to identify the right targets for the action of anti-retroviral drugs. Various aspects of HIV replication cycle, viz., cell types, cell receptor/s, process and mechanism of receptor-ligand 
binding, integration of viral genome to the host cell genome, production of new virions, etc., have been studied in great depth. Due to better understanding about HIV replication, it is now possible to develop various groups of anti-retroviral drugs (ARDs). These ARDs have been very effective to control HIV infections, but these ARDs are still unable to cure HIV.

The most characteristic feature of HIV is the genetic material itself. The genetic material of HIV is RNA not the DNA. RNA as a genetic material is a very unique feature of retroviruses. Usually the genetic information is transferred from one generation to the next by DNA, because DNA is known as genetic material for living organisms. The problem about transfer of genetic information from one generation to the next in case of retroviruses has been overcome due to the presence of unique enzyme called reverse transcriptase (RT). RT enzyme can reverse-transcribe RNA into DNA. Reverse transcription is an essential part of replication cycle of HIV. HIV cannot replicate itself in the absence of host/host cells because HIV does not have its own synthetic machinery. Hosts' cells compensate the requirement for the synthetic machinery for HIV replication. Replication of HIV starts only after the hosts' cells get infected with HIV. For HIV replication, it is essential that virion should attach to the specific receptor present on these target cells, and then the replication process continues till the production and release of new virions takes place (Freed 2001). T-cells are the main cells for HIV infections. The process of HIV replication has been divided into five different steps (Fig. 7.2):

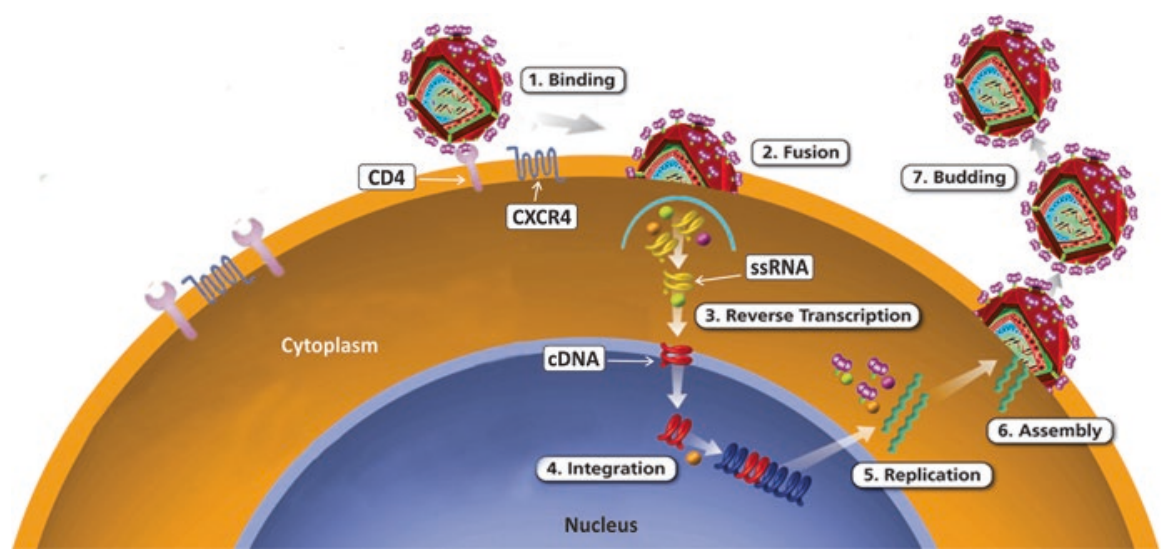

Fig. 7.2 HIV Replication

Schematic representation of different step of HIV replication. During infections, HIV attaches to the CD4 receptor on cell surface of target cells permissive for HIV. After attachment, HIV fuses with the cell membrane of target cells. HIV RNA and other proteins are released inside the target cell after attachment and fusion of HIV with plasma membrane. After activation, reverse transcriptase enzyme produces pro-viral DNA in cytoplasm. Now pro-viral DNA moves to the nucleus and gets integrated with the genome of host cells with the help of integrase enzyme of HIV. After integration to the host cell genome, pro-viral DNA produces mRNA. Newly synthesized viral mRNA translates into different types of viral proteins necessary for the production of new virions. Viral proteases cleave these proteins for the assembly of new virions. These new virions are released into host circulation from the infected cells, Viral RNA; pro-viral DNA 
1. Viral attachment and viral entry

2. Reverse transcription

3. Integration of pro-viral DNA

4. Transcription and translation

5. Completion and release

\subsubsection{Viral Attachment and Viral Entry (to the Cell)}

The first and the essential step of viral (HIV) replication cycle is the attachment of viral particle to the target cells. Interaction of virus to the cells is like a ligandreceptor binding phenomenon. A specific ligand is present on virus, while a specific receptor is present on the target cells. In case of HIV, CD4 is the main receptor, while ligand is gp120. CD4 is the main receptor for the attachment of HIV to the target cells, i.e., T-cells. CD4 is a $58 \mathrm{kDa}$ glycoprotein present at the cell surface of a specific T-cell population which is also known as T-helper cell or $\mathrm{CD}^{+}{ }^{+} \mathrm{T}$-cells. Apart from T-helper cells, CD4 receptors are also present on some other cell types, viz., monocytes, macrophages, dendritic cells, microglial cells, etc. The binding of gp120 to CD4 is the first and most essential step for the entry of HIV into the permissive cells. The binding can occur due to the attachment of HIV to CD4 cells. Attachment occurs when T-helper (permissive) cells and HIV are present in closer vicinity.

The attachment and entry of HIV into T-cells takes place due to the presence of two different envelop proteins present at the surface of HIV. These proteins are glycoprotein 120 (gp120) and glycoprotein 41 (gp41). Out of these two glycoproteins, gp120 binds with CD4 receptor and induces conformational changes. The conformational changes in gp41 lead to the unfolding of gp41 allowing gp41 to move toward the surface of same T-cells and bind to co-receptors. The two types of co-receptors essential for HIV replication are (1) CXCR4 and (2) CCR5 (Benger et al. 1999). Binding of gp120 and gp41 to the cell surface through the specific receptor on cells leads to the fusion of viral envelop with the plasma membrane of the target cells. The fusion of viral envelop with plasma membrane of the target cells is the most crucial step for the entry of HIV to the target cells (Fenouillet et al. 2001). Fusion of viral envelop to the cell membrane paves the path for the delivery of HIV genome and other HIV proteins to the host cells. Delivery of viral genome and viral proteins to the target cells is an essential step to initiate HIV replication cycle.

Binding of virus to the target cells leads to the fusion; therefore the fusion step is one of the interesting targets for the development of new anti-HIV drugs. Although blocking of fusion step of HIV replication cannot be the most effective means to control HIV infections, drugs which can block the entry of HIV to the target cells could also be an effective means to prevent the HIV entry to the new target cells after the production and release of new viruses from infected cells (Ryser and Fluckiger 2005). Realizing the significance of fusion inhibitors, active researches are going on to develop more effective fusion inhibitors. Some of the fusion inhibitors are, e.g., Fuzeon, etc. 


\subsubsection{Reverse Transcription}

Viral genome and proteins are delivered to the target cells after the fusion of HIV with the target cells. Untill this stage RNA is the viral genome, the next step of HIV replication cycle is to convert RNA into DNA. This conversion is accomplished by the activity of reverse transcriptase enzyme of HIV. After release of HIV components into the cytoplasm of target cells, the RT enzyme starts working by making copies of viral RNA into complementary DNA (c-DNA). The new synthesized DNA produced from viral RNA is called "pro-viral DNA." On the one hand, RT is an advantage to HIV, while on the other hand, HIV-RT has been a major disadvantage for drug development because HIV-RT lacks the ability for "proofreading" of DNA. Due to the inability of RT to do DNA proofreading, the process for pro-viral DNA synthesis is highly prone to errors. The inability of proofreading by RT is an advantage for HIV for its survival, but at the same time this has been a great disadvantage for the treatment of HIV infections. Inability to proofread leads to rapid generation of mutations in HIV. These mutations are the major reason for resistance in HIV against ART.

The production of pro-viral DNA due to the activity of RT enzyme has been the most attractive target for the drug development. The simple rationale to target this step by drug is to block or inhibit the production of new pro-viral DNA. If one can stop production of new pro-viral DNA, then HIV infection can be controlled effectively. This approach did not turn out to be as easy as it was conceptualized earlier. The major stumbling block for the development and treatment of HIV infections is none other than the inability of RT to do proofreading.

Majority of anti-retroviral drugs (ARD) have been developed to target RT step of HIV replication. These drugs are grouped as nucleoside reverse transcriptase inhibitors (NRTIs), nucleotide reverse transcriptase inhibitors (NtRTIs), and nonnucleoside reverse transcriptase inhibitors (NNRTIs). Different drugs of these classes are known to inhibit RT activity of HIV with different mechanisms. The advantage of these drugs is that different analogues can be used alternatively to address the concerns of drug resistance developed against any of these drugs. After evolution of resistance to one analogue, another analogue can be used for treatment of HIV infection, e.g., zidovudine, lamivudine, stavudine, etc.

\subsubsection{Integration of Pro-viral DNA}

After the production or synthesis of pro-viral DNA, it is essential that pro-viral DNA must integrate with target cell genome to produce new progeny of HIV. This step is known as integration. Integration of pro-viral DNA takes place due to the enzymatic activity of integrase (In) enzyme. Integrase is a viral enzyme in origin. HIV genome has nine genes in total which are flanked by long terminal repeat (LTR) on either sides. So LTR of viral genome and enzyme of viral origin are essential for the integration of pro-viral-DNA to the genome of host cell. 
Integration step has turned out to be an excellent target for development of new drugs which can stop HIV replication. Rationally, if one can stop the viral integration to the genome of target cell, then further replication steps will not proceed. Integrase inhibitors work in combination with other drugs. Integrase inhibitors alone are not very effective to treat HIV infections. But integrase inhibitors can be an excellent choice of drug to deal with drug resistance against HIV. Some of the drugs of this group were approved by FDA in 2007, e.g., Isentress.

\subsubsection{Transcription and Translation}

After integration of pro-viral DNA in the genome of target (host) cells, transcription and translation of viral gene starts for the production of new virions. In certain circumstances, pro-viral DNA gets integrated in the genome of target, but integrated pro-viral DNA does not start active transcription and translation. This is the reason these cells do not show signs for active replication of HIV. Cells with integrated pro-viral DNA remain latently infected. This phenomenon is called as latent infection. At some point of time, latently infected cells start active replication of HIV, but still there are no concrete answers for the trigger of active replication. With time, it is getting clearer that latently infected cells are one of the major hurdles to find a cure for HIV.

After integration various transcriptional factors of host/target cells get activated. These host transcription factors support transcription of viral RNA with help from cellular RNA polymerases. Splicing of RNA transcripts takes place in a planned manner. Transcription leads to the production of mRNA to synthesize various viral proteins in cytoplasm of host cells. Tat and Rev are two different proteins that are produced at this stage and support HIV replication in activated T-cells. Env and Gag proteins are produced at a later stage. After the production of gag proteins, new viral RNA molecules (full-length) bind with gag proteins and are packed as new virions.

\subsubsection{Assembly and Release}

Assembly and release of new virions is the last and final stage of HIV replication cycle. At this stage Env passes through the cytoplasmic reticulum and finally gets transported to Golgi complex. Env proteins undergo proteolytic cleavage in Golgi complex. After proteolytic cleavage, Env produces two different glycoproteins, i.e., gp120 and gp41. Now gp120 and gp41 move toward the plasma membrane of host cell. At this stage gp41 anchors gp120 to the cell membrane of infected cells. Now, gag-pol polyproteins help in the budding of new virions from infected host cells. Proteases from HIV cleave three polyproteins which result into various functional HIV proteins and HIV enzymes. Cleavage of polyproteins completes the maturation and release of new infective virions. 
This step is also an interesting target to stop HIV replication. This is the reason that various protease inhibitors (PIs) are used as drugs. If these PIs can prevent the activity of HIV protease that will prevent the completion and maturation of infective HIV, this prevents further infection. This step of HIV replication can be blocked by protease inhibitors, e.g., lopinavir, ritonavir, etc.

\subsection{Anti-retroviral Drugs}

Nonavailability of any drug to treat HIV/AIDS patient was the major hurdle at the time when initial cases of HIV/AIDS were reported in the year 1981. It took almost 6 years before the first drug to treat HIV/AIDS infection was approved by the US Food and Drug Administration (USFDA or FDA), Maryland, USA. USFDA approved azidothymidine (AZT) as the first drug to treat HIV/AIDS in the year 1987. Drugs to treat HIV infections are also commonly called as anti-retroviral drugs (ARD) or anti-HIV drugs. Some of the common retroviral infections are caused by human T-cell leukemia virus-1 (HTLV-1) and human T-cell leukemia virus-2 (HTLV-2). Interestingly HTLV-1 and HTLV-2 are slow-growing viruses compared to HIV. The incubation period for HTLV-1 and HTLV-2 is very long, almost about $30-40$ years.

The enhanced morbidity and mortality associated with HIV infections was really a matter of concern and worry to various sections of society. These serious concerns were the engines to find a cure for HIV by developing new drugs which can treat HIV infections. Thank God! Serious and sincere efforts in this area have been fruitful to develop numerous new drugs to control HIV infections. In the meantime, a better understanding about HIV replication evolved which helped in identification of targets for new drugs which can either block or inhibit HIV replication. Blockage or inhibition of HIV replication can be one of the means to cure HIV, may be in the future, but not at the present time.

Unfortunately, a cure for HIV is still not on the horizon, but a possibility in the future to find a permanent cure for HIV/AIDS cannot be denied. Knowledge about the different crucial steps of HIV replication cycle has been helpful in the development of different groups of medications, and those are (1) nucleoside reverse transcriptase inhibitors (NRTIs), (2) nucleotide reverse transcriptase inhibitors (NtRTIs), (3) non-nucleoside reverse transcriptase inhibitors (NNRTIs), (4) protease inhibitors (PIs), and (5) integrase inhibitors (InIs) (Table 7.2). Apart from these well-established group of ARD, some new types of drugs are under active investigation like fusion inhibitor, etc.

\subsubsection{Nucleoside Reverse Transcriptase Inhibitors (NRTIs)}

As the name of the drug suggests, these drugs blocks the activity of reverse transcriptase enzyme. Basically these drugs act as "false building block" for HIV replication cycle serving as an alternative substrate for RT enzyme. Mechanistically, 
Table 7.2 Anti-retroviral drugs

\begin{tabular}{|c|c|c|}
\hline Class & Generic name & Chemical name \\
\hline \multirow{2}{*}{$\begin{array}{l}\text { E.I. or } \\
\text { F.I }\end{array}$} & Enfuvirtide & $\mathrm{T}-20$ \\
\hline & Maraviroc & MVC \\
\hline Int.I & Raltegravir & RGV \\
\hline \multirow{7}{*}{ NRTI } & Abacavir & $\mathrm{ABC}$ \\
\hline & Azidothymidine & AZT \\
\hline & Didanosine & ddI \\
\hline & Lamivudine & 3TC \\
\hline & Stavudine & $\mathrm{d} 4 \mathrm{~T}$ \\
\hline & Zalcitabine & $\mathrm{ddC}$ \\
\hline & Zidovudine & ZDV \\
\hline \multirow[t]{4}{*}{ NNRTI } & Delavirdine & DLV \\
\hline & Efavirenz & EFV \\
\hline & Etravirine & ETR \\
\hline & Nevirapine & NVP \\
\hline NtRTI & Tenofovir & TDF \\
\hline \multirow[t]{8}{*}{ PI } & Atazanavir & ATV \\
\hline & Amprenavir & APV \\
\hline & Indinavir & IDV \\
\hline & Lopinavir & LPV \\
\hline & Nelfinavir & NFV \\
\hline & Ritonavir & RTV \\
\hline & Saquinavir & SQV \\
\hline & Tipranavir & TPV \\
\hline
\end{tabular}

E.I. Entry Inhibitors, F.I. Fusion Inhibitors, Int. I Integrase Inhibitors, NNRTI Non-Nucleoside Reverse Transcriptase Inhibitors, NRTI Nucleoside Reverse Transcriptase Inhibitors, NtRTI Nucleotide Reverse Transcriptase Inhibitors, PI Protease Inhibitors

NRTIs compete with physiological nucleoside during pro-viral DNA synthesis. NRTIs are designed in such a manner that azido group is added to ribose sugar. The presence of azido group serves as a chain terminator for DNA synthesis. During synthesis of pro-viral DNA, the presence of NRTI terminates DNA synthesis. Termination of DNA synthesis stops further synthesis of new DNA for completion of HIV replication. The first anti-retroviral drug azidothymidine belongs to this group. Apart from thymidine, some other nucleosides have been added in this group of medicine, and those are adenine (A), cytosine ${ }^{\odot}$, and guanosine $(\mathrm{G})$. Some of the most common NRTIs are Azt, ddI, ddc, d4T, 3TC, and FTC. Out of these different drugs, Azt and d4T are thymidine analogues, FTC and 3TC are cytosine analogues, $\mathrm{ddI}$ is an adenosine analogue, and ABV is a guanosine analogue.

On one hand discovery of NRTIs was a great relief for the treatment of HIV patients, while on the other hand drug resistance turned out to be a major bottleneck for the effective use of NRTI for the treatment of HIV patients. The problem of drug resistance is attributed to the inability to do DNA proofreading by RT of HIV. This feature of RT has been an advantage for HIV to survive under drug pressure. Additionally the development of different analogues for the NRTI group of 
medicine has been a great advantage to the clinicians to overcome or to deal with the problem of drug resistance up to a greater extent.

\subsubsection{Nucleotide Reverse Transcriptase Inhibitors (NtRTIs)}

Another version of NRTI is NtRTI group which uses nucleotides instead of nucleosides. NtRTIs have some advantages over NRTI. This NRTI group of drugs has to be activated to show its anti-retroviral and inhibitory activities by converting nucleoside into nucleotide. Therefore, NtRTIs have an added advantage to skip this step of activation to perform inhibitory activities of drug. This is the reason that NtRTIs are more toxic compared to the drugs of NRTI group. The mode of action of NtRTI is similar to NRTI, but NtRTI is known to be presented with more side effects. Tenofovir disoproxil fumarate (TDF) is a NtRTI. TDF is commercially available as Viread. Nowadays NtRTI is available in various combinations, but a combination of TDF with ddI should be avoided.

\subsubsection{Non-nucleoside Reverse Transcriptase Inhibitors (NNRTIs)}

This is another group of drug which also inhibits the activity of RT enzyme, but the mechanisms of action of NNRTIs are different than the mode of action of NRTI or NtRTI. NNRTI binds directly to RT enzyme. NNRTIs interfere with the active (catalytic) site of RT enzyme, so NNRTIs affect the normal functioning of RT enzyme by binding close to the substrate binding sites (i.e., dNTP binding site). The binding of NNRTI to RT enzyme prevents the nucleoside binding to the catalytic site. Binding of NNRTI to RT enzyme does not require any further activation (Boehringer Ingelheim Pharmaceuticals Incorporated 2005). The example of NNRTI group of drugs is nevirapine, delavirdine, efavirenz, etc.

\subsubsection{Integrase Inhibitors (Inls)}

Integration of pro-viral DNA into the genome of infected cells occurs due to the activity of integrase enzyme. Integrase enzyme has been studied as one of the potential drug targets to control HIV replication. USFDA has approved a drug in this category in 2007 though InIs alone cannot control HIV infection, so integrase inhibitors have to be given in combination. Raltegravir, the only drug of this group, is available in the market as Isentress.

\subsubsection{Protease Inhibitors (PIs)}

As the name suggests, this group of medicine inhibits the activity of protease enzyme. PIs inhibit the activity of viral proteases (proteases of HIV). During HIV 
replication cycle, the role of viral proteases is very important for maturation of viruses. Protease is a homodimer comprised of 99 amino acid monomers. HIV protease cleaves gag and gag-pol polyproteins which are precursors to produce mature and active proteins, and these proteins are protease, reverse transcriptase, RNase $\mathrm{H}$, and integrase. This is the reason viral protease is an important drug target. Protease inhibitors block active site of enzyme so that viral proteases cannot function. A nonfunctional viral protease produces immature and non-infective virions, so a protease inhibitor can reduce or inhibit the production of new virions from infective cells. HIV can still replicate in the presence of PI but will not be able to form a mature virus. PIs are essential components of combination therapy, i.e., HAART. Use of PIs has reduced the problem of drug resistance. Toxicity and side effects are common with PIs. Some of the common PIs are indinavir, lopinavir, nelfinavir, ritonavir, etc. (Saag et al. 2018).

\subsubsection{Fusion Inhibitors (FIs)}

The first step for HIV infection is the interaction of HIV with receptor and coreceptors present on cells. This interaction takes place through gp120 and gp41 of HIV. Interaction leads to fusion of HIV to plasma membrane of HIV-permissive cells. gp41 plays an important role in initial step involving fusion of HIV with permissive cell envelop. This step is a good target to prevent HIV infections. One drug as fusion inhibitor was approved by USFDA in 2003. The brand name of the drug is Fuzeon which is also called as T-20. Fuzeon is a polypeptide comprising of 36 amino acids. Since Fuzeon is a polypeptide, this drug is not orally bioavailable. Bioavailability is one of the major drawbacks associated with FIs. This medicine can be injected parenterally (subcutaneous). One injection a day does not offer the expected result, but twice a day regimen of FI is useful to demonstrate its effect. FIs are good in combination therapy.

\subsection{Anti-retroviral Treatment and HIV Drug Resistance}

The first drug to treat HIV infections was azidothymidine (Azt). Azt was a very effective drug, and soon drug resistance was commonly observed among HIV patients with the use of Azt. The main culprit for the development of drug resistance was none other than the inability of RT (HIV) enzyme to perform the function of DNA proofreading. A consistent increase in the cases for drug resistance led to development of new modalities to treat HIV patients. To discuss all possible treatment modalities and to deal with drug resistance are beyond the scope of this chapter; therefore we have discussed three most commonly used treatment modalities for HIV seropositives who are presented with symptoms of drug resistance (Olender et al. 2012). 


\subsubsection{Highly Active Anti-retroviral Treatment (HAART)}

HAART is a new name given to the kind of combination therapy for HIV patients. HAART has became a reality due to the availability of different classes of drugs. Drugs from different classes not only have different mechanism actions, but these drugs also work to block different steps of HIV replication. HAART regimen has been widely accepted since 1996 to treat patients facing the problem of drug resistance. Regimen for HAART was developed and decided by a panel of experts from the National Institutes of Health and other international organizations. Basically HAART uses a combination of three or more anti-HIV drugs, preferably from different classes. HAART has various advantages like the following: (1) HAART reduces the complexity of dose scheduling, (2) HAART reduces the problems related to the complex drug schedules and regimen, (3) HAART is helpful to achieve synergism between drugs used to treat HIV infections, (4) HAART reduces the drug toxicity with the decrease in the doses of different drugs, (5) HAART decreases the possibility for the development of drug resistance, and (6) HAART targets various steps of HIV replication, Therefore HAART can be very effective to control HIV infections. So many advantages associated with HAART have been the reason for effective use of HAART regimen. It is difficult to realize or even to recognize the probable number of combinations that can be used in a HAART regimen. So far $\sim 25$ different drugs are licensed to be used as anti-HIV drug.

\subsubsection{Salvage Therapy}

As the name suggests, salvage therapy is to salvage the patients from the limitations of available medications to treat HIV infections. In certain cases it has been observed that even HAART therapy is unable to give the expected outcome with reference to control over HIV infections. Then salvage therapy is recommended for the treatment. In principle salvage therapy can also be recognized as mega-HAART therapy. In salvage therapy more numbers of drugs are used compared to HAART regimen. Salvage therapy is used among those patients who are either resistant or nonresponder to other anti-HIV treatment strategies (Tang and Shafer 2012). In the case of salvage therapy, up to nine different drugs are given to HIV/AIDS patient in the form of combination therapy. Certainly salvage therapy is an expensive therapy with some serious side effects. Side effects of salvage therapy could either be bearable or unbearable too.

\subsubsection{Drug Holiday}

As the name suggests, during these treatment protocols, drugs go on a holiday. It means patients are not given any anti-HIV drug for certain period of time before patient starts taking anti-HIV drug again. Drug holiday regimen is evolved to address the problem of drug resistance. The theoretical foundation for this protocol 
is that withdrawing the drug selection pressure in HIV patients will make HIV or new virion more susceptible to the drug. This can also be called as "drug interruption therapy." Drug holiday regimen has shown promising results.

\subsection{How to Test Anti-HIV Drug}

Since the discovery of HIV as a causative agent for AIDS, there was a dire need to develop an assay for the testing of anti-retroviral activity of different anti-retroviral drugs or agents. Nonavailability of any suitable animal model for HIV infections is one of the major hurdles to evaluate anti-retroviral drugs in vivo. So, scientists have developed various in vitro assays to evaluate toxicity and anti-retroviral activity of anti-HIV drugs. This test is based on the survival of cells infected with HIV in the presence of anti-retroviral drugs or anti-HIV drugs. These in vitro assays have been adopted in a format to evaluate anti-HIV drugs even on a large scale. The basic principle to evaluate anti-HIV drugs is to assess either cell death or cell viability in the presence of anti-HIV drugs. The advantage of this assay is that one can evaluate two important aspects of anti-HIV drugs, and those aspects are (1) to evaluate toxicity of anti-HIV drugs and (2) to evaluate the anti-HIV effect. These tests are called as MTT assay for the evaluation of anti-HIV drugs.

\subsection{MTT Assay for the Evaluation of Anti-HIV Effect of Anti- retroviral Drugs}

The basic foundation of this assay is to evaluate the cell death or cell mortality of HIV-permissive cells in the presence of infective HIV as well as drug/s. A 96-well format is a miniature form of the assay so that a large number of samples can be tested with convenience. These two are the characteristic features of MTT assay. This is the reason that MTT assay has been adopted for ART testing.

In this anti-HIV drug assay, MTT dye is used. MTT dye gets metabolized by mitochondrial enzyme to give a blue-colored formazan product. The conversion of formazan from MTT dye is only possible due to the enzymatic activity of mitochondrial enzyme. Mitochondrial enzyme works only in living cells so dead cells do not convert MTT dye into formazan. The intensity of blue color is the end point for the determination of cell viability or cell death. The cell viability in this assay is indicative of toxicity when used for drug toxicity assay and anti-HIV effect when used for the evaluation of anti-HIV effect of drug which is under investigation.

When MTT is added to the cells, the mitochondrial enzyme converts yellow color of MTT dye into blue color crystals of formazan. These crystals are finally dissolved into organic solvent and Optical Density (OD) of sample is monitored. If someone is working in the linear range of assay, then cell viability is directly proportional to the OD of sample. MTT assay is very versatile in nature and can be 
easily adopted for a 96-well plate format. Adaptation of MTT assay for testing of anti-HIV drug has numerous advantages like the following:

1. Large number of samples can be tested.

2. Number of drugs can be tested at the same time.

3. Various concentrations of drugs can be tested at the same time.

4. The requirement of number of cells needed for assay is very low.

5. A lesser number of HIV virions are needed.

6. It is an efficient and effective method for the testing of large number of samples at any single given time. To evaluate the anti-HIV effect, the following steps are needed: (1) growing of HIV-permissive cells, (2) plating of cells, (3) infection of cells with HIV, (4) addition of anti-HIV drugs, (5) addition of MTT, (6) stopping of MTT reaction, (7) acquisition of data, and (8) analysis of data (Zhu 2005; Peters et al. 2013).

\subsection{Rationale of Each Essential Step}

\subsubsection{Growing or Culturing of HIV-Permissive Cells}

For the evaluation of anti-HIV drugs, we need to use cells permissive for HIV. It means cells must be $\mathrm{CD}^{+}$. The most commonly used cells are T-cells which can be either primary cells like PBMCs or secondary cells or cell lines like MT-4, HUT 78 , $\mathrm{H}-9$, etc. Cells have to be grown overnight for their use in this assay.

\subsubsection{Plating of HIV-Permissive Cells in 96-Well Plate}

Overnight grown cells have to be washed and counted. A single cell suspension with the required cell density in required number of wells of the 96-well plate. (Usually $2 \mathrm{x}$ concentration of cells is added into the wells, so that drug concentration can also be used 2x. After mixing contents in each well, cells and drug will be diluted in a 1:1 ratio. The final concentration of cells and drug in each well would be $1 \mathrm{x}$ or the desired concentration.)

\subsubsection{Thawing of HIV Stock}

To infect cells in a 96-well plate, one has to thaw an HIV stock of known titer (various expressions of titer are used like MoI, RT, p24, etc.). After thawing, appropriate dilution has to be added into each well in specific volume for HIV stock. HIVinfected cell will show cell death at the end of assay, and effective concentration of anti-HIV drug will prevent cell death caused by HIV. 


\subsubsection{Preparation of Drug Dilution}

One has to use nontoxic concentrations of drug to test anti-HIV activity of the drug under investigation. Initially it is advisable to try five different concentrations or dilutions of drug and to use dilutions of drug/s in log fold (e.g., 2x, 5x, 10x, etc.). Drug dilutions should be prepared, giving due consideration for the volume of drug to be added into specific wells.

\subsubsection{Addition of Drug to the Wells}

After calculating the drug concentrations, the required volume of drug has to be added to the respective wells. Remember to add the drug to the respective well so that anti-HIV effect of drug can be evaluated at termination of anti-HIV assay.

\subsubsection{Incubation of Drug and HIV with Cells}

After addition of cells, HIV and candidate drug have to be incubated at 37C with 5\% $\mathrm{CO}_{2}$ and $95 \%$ humidity in an incubator. The incubation period has to be empirically determined. It can vary from $24 \mathrm{~h}$ to 7 days. Numerous factors like cell counts, HIV titer, and cell death should be taken in account for the determination of incubation period.

\subsubsection{Addition of MTT Dye}

At the end of incubation, MTT dye has to added to the wells of a 96-well plate to evaluate anti-HIV effect of drug on HIV-permissive cells. After addition of MTT dye to respective wells, MTT has to be mixed properly in each well. Mixing of MTT can be achieved either by plate mixer or by multichannel pipette. After mixing of MTT dye, a 96-well plate is incubated, so that mitochondrial enzyme of live cells can metabolize MTT to produce formazan crystal of blue color.

\subsubsection{Stopping the MTT Reaction}

After addition of MTT at certain of time, MTT reaction has to be stopped by addition of stopping solution into respective well. Stopping solution has to be mixed in wells to dissolve formazan crystal, and mixing can be done by using either plate mixer or multichannel pipette. 


\subsubsection{Reading of Plate}

After mixing of stopping solution, the OD of each well has to be read at specific wavelength using ELISA plate reader, and data must be stored for analysis. Data sheet must have details of experiment like cell type, HIV type, drug, drug concentration, etc.

\subsubsection{Calculating the Data}

The OD values of different wells are used to compare the viability of cells in that specific well or group of well with different treatments. On the basis of viability of cells, one can determine the anti-HIV effect as well as the most effective concentration of drug for its anti-HIV effect.

\subsection{Important Note}

To set up a 96-well plate, it is important to prepare the chart or map for the plate with all the relevant information present on it. Preparation of chart is very helpful to interpret result without any errors or omissions. While setting up an experiment in a 96-well plate, each plate must have the following necessary components:

1. Blank well (only media)

2. Cell control well (only cells, no HIV and no drug)

3. Drug control well (cells and drug, no HIV)

4. HIV control well (cell and HIV, no drug)

5. Positive HIV control well (cell and HIV, no drug)

6. Experimental well (Cell, HIV, and test drug)

\subsection{NeuroAIDS}

Improvement in the area of anti-retroviral drugs is enormous. The first drug to treat HIV infection was approved by the USFDA in 1987. The first ever drug approved for the treatment of HIV infection was zidovudine, and since then many more drugs have been developed and available to treat HIV infections. These ADTs belong to different groups of drugs, i.e., NRTI, NtRTI, NNRTI, protease inhibitors (PIs), integrase inhibitors (InIs), and even the fusion inhibitors (FIs). Since a variety of drugs are now available which can simultaneously target different stages of HIV replication, at present it can be said that the problems of drug resistance have been addressed very effectively due to availability of different drugs. As a result of the availability of better anti-retroviral drugs for HIV patients, now an HIV seropositive can lead a quality life like a normal person. These drugs have prolonged the asymptomatic stage among HIV seropositives which now extends for 20 years or more. 
But no one ever recognized or realized that some of these advantages to treat HIV seropositives may turn out to be a double-edged sword. On the one hand, these improved medications have extended the life span of HIV seropositives, while on the other hand, these advantages have led to new health complications among HIV seropositives. These new complications in HIV seropositives are now grouped as NeuroAIDS. So, what is neuroAIDS? And what are the consequences of neuroAIDS?

NeuroAIDS is really a matter of serious concern due to very high prevalence of neuropsychiatric complications among HIV seropositives. The prevalence of neuropsychiatric complications among the general population is $\sim 10-15 \%$, while prevalence of neuropsychiatric complications has been reported $>50 \%$ among HIV seropositives. Various neuropsychiatric complications are HIV-associated dementia (HAD), HIV-associated encephalopathy (HIVE), HIV-associated minor cognitive and motor disorder (MCMD), etc. (McArthur et al. 2005). Presently, different types of neuropsychiatric complications in HIV/AIDS patients have been grouped as neuroAIDS (McCombe et al. 2009). It seems like neuroAIDS is another epidemic waiting to happen in the near future (Power et al. 2009). Some of the common neuropsychiatric complications in the case of neuroAIDS have been mentioned in Table 7.3.

Addition of new infections along with the improved survival of HIV seropositives is the main reason for increase of numbers of HIV/AIDS patients among an already existing pool of HIV patients. This new change in demography of HIV/ AIDS is a matter of concern for all of us.

These neuropsychiatric complications among HIV seropositives are known to affect both central nervous system (CNS) and peripheral nervous system (PNS). CNS is one of the most well-protected organ systems of the body. CNS is protected by the blood-brain barrier (BBB) which regulates the entry of any biomolecule in the CNS. The reasons or causative factors for the development of neuroAIDS get more intriguing by knowing the fact that most of the cells in CNS are not permissive to HIV and neurons in particular. Most of the cells of CNS are non-permissive to HIV because cells of CNS do not express receptors for HIV infections. Entry of $\mathrm{HIV}$ to the brain is also not possible due to the very fine control of the BBB. One of the most probable answers for HIV infections to CNS can be explained on the basis of "Trojan horse hypothesis." As per the assumption of this hypothesis, HIV enters

Table 7.3 NeuroAIDS: neuropsychiatric disorders

\begin{tabular}{l}
\hline Addiction \\
\hline Anxiety \\
\hline Depression \\
\hline Epilepsy \\
\hline Mania \\
\hline Mood disorders \\
\hline Neurocognitive impairment \\
\hline Neuropathic pain \\
\hline Physical disability \\
\hline Seizures
\end{tabular}


into the CNS through the HIV-infected cells from systemic circulation like monocytes or T-cells. These infected cells may find their entry to the brain due to alteration in the permeability of BBB (Verma et al. 2010). There could be various factors and reasons for alteration in the permeability of BBB. After entry of infected cells to the brain, these cells remain latently infected and remain in the brain for a long period of time. At certain point of time, these latently infected cells may start HIV replication. The trigger for the activation of these latently infected cells is not known or not yet well defined, but active replication of HIV in the brain could lead to the production of various other biomolecules of viral origins. In turn these biomolecules may start or initiate the induction as well as production of different proinflammatory and inflammatory cytokines in the local milieu. Certainly these pro-inflammatory and inflammatory cytokines are important in protective immune response, but in CNS these biomolecules could induce neuronal death via apoptosis. Since neurons do not regenerate, therefore inadvertent loss of neurons could lead to permanent damage to CNS or the brain (Olivier et al. 2018).

According to a recent study, only $30 \%$ of HIV-infected children living in subSaharan Africa are receiving anti-retroviral therapy. The situation is quite worrisome as an estimated 2.3 million children less than 15 years of age are infected with HIV in sub-Saharan Africa. These children may manifest mild to severe neurocognitive disorders with psychiatric symptoms in the long run (Wilmhurst et al. 2018). As per some estimates, NeuroAIDS may have potential to become one of the major health concerns among long-term HIV seropositives who are under proper antiretroviral treatments. Some of the major concerns for neuroAIDS patients are the following: (1) the total number of HIV/AIDS patients is increasing globally on a daily basis; (2) among the majority of HIV seropositives, neuroAIDS hits them at the prime of their life span, e.g., mostly between the age group of 35 and 45; (3) symptoms of neuroAIDS render these patients least productive in their prime of life; (4) neuroAIDS results in substantial loss of either individual or family income; (5) need of a caretaker causes extra burden to financial resources of the family or individuals; (6) ART is already an expensive treatment, and further additional cost for the treatment of neuroAIDS just exaggerates or worsens the financial situation; etc.

Realizing the potentials and consequences of neuroAIDS at personal level, family level, as well as society level, it is very important to direct financial resources toward the better understanding about neuroAIDS as well as to find a cure for neuroAIDS.

\subsection{Berlin Man: An Example for HIV Cure}

It has been $>35$ years since the initial cases of HIV/AIDS have been reported in 1981. Serious, committed, and dedicated research efforts in the area of HIV/AIDS have been quite successful to bring a better control over the HIV/AIDS epidemic. Still a cure for HIV/AIDS is far from reality. Everyone in this world still have a hope that one day we will be able to find a cure for HIV/AIDS. The question is how? and when? Some of the probable answers do come from the nature itself!!! Some clues 
can be drawn from elite controllers and long-term non-progressors with reference to HIV infections. One and the only example for this approach is none other than the "Berlin man." Berlin man is an HIV-positive patient who has undergone bone marrow transplantation (hematopoietic stem cell transplantation) from a healthy donor. Since the bone marrow transplantation, Berlin man remained free from HIV infections for more than 10 years by now. So what was the reason for bone marrow transplantation in this patient? What are the scientific rationales for the success behind this new and probable cure for HIV?

High awareness about HIV/AIDS was the reason for active participation of people in different HIV/AIDS programs and frequenting HIV/AIDS clinics. Information was collected from certain individuals, who were classified under high-risk category to contract HIV based on their lifestyles. The most interesting observation was that even though these individuals were following a high-risk lifestyle they did not get infected with HIV. The value for this observation was further added with a known fact that these high-risk individuals were never on any type of anti-retroviral treatments. Therefore, it was concluded that there are very good possibilities that these high-risk individuals for HIV/AIDS may have some kind of "natural resistance" against HIV infections. This natural resistance in these individuals prevents HIV infections to them, even though they are following a high-risk lifestyle.

Further studies indicated that the T cell co-receptors may be responsible for the resistance against HIV infections among these high-risk individuals. At this stage it is important to reiterate that the primary receptor of HIV infections is CD4 receptors, but co-receptors are also important for HIV infections along with the requirement of primary receptors. Two different types of co-receptors have been identified for HIV infectivity, and these two co-receptors are CXCR4 and CCR5. On the basis of requirement of co-receptors for HIV infectivity, even HIV strains are divided into two categories. HIV strain which needs CXCR4 co-receptor for its infectivity is called as X-4 strain, and the HIV strain which requires CCR5 for its infectivity is called R5.

The extensive researches have demonstrated that these high-risk individuals which are resistant to HIV infection are presented with mutation in one of the coreceptors, i.e., CCR5. This mutation is a deletion mutation for CCR5 gene. A 32 bp sequence of DNA was found to be deleted in these individuals. Due to deletion of $32 \mathrm{bp}$, this mutation is known as $\Delta 32$ deletion. Story about the mutation of CCR5 co-receptors gets further complicated due to homozygous nature of mutation as well as heterozygous nature of mutation. It was observed that individuals with homozygous mutations for $\Delta 32$, i.e., CCR5 $\Delta 32 / \Delta 32$, are fully resistant to HIV infections. On the other hand, individuals with heterozygous mutation were presented with a slow progression of disease even after the exposure to HIV. So far, it has been reported that $\Delta 32$ mutation CCR5 exists only among Caucasians. The frequency of CCR5 $\Delta 32$ mutation is very low. The frequency of this mutation among Caucasian population is merely $\sim 1-3 \%$. This observation has significant clinical significance toward a possible cure for HIV. Such a low frequency for this mutation could be a 
major bottleneck for the application of this clinical approach for the treatment of HIV seropositives along with other relevant aspects related to it. A low frequency of this mutation among Caucasians must not discourage us to make this as a possible cure for HIV. There are numerous advancements in the area of gene therapy and stem cell research which may add value to this strategy as one of the probable cures for HIV. So far, Berlin man has remained a success story for the cure of incurable HIV infections.

As mentioned in the previous paragraphs, Berlin man has earned reputation as the first case to testify the significance of CCR5 $\Delta 32 / \Delta 32$ mutation with a probable potential to cure HIV. Berlin man is a 40-year-old Caucasian male who was HIV positive for $>10$ years. He has an excellent control over HIV because he was on HAART regimen. But problem started with him when he was diagnosed with acute myeloid leukemia (AML). This patient was not responding to the AML treatment. Under these circumstances except allogeneic bone marrow transplantation, this patient was left with no other choices for the treatment of AML. At this point of time, the surgeon who was treating this patient took extra precautions for allogeneic bone marrow transplantation. The surgeon chose to do the bone marrow transplantation from a donor carrying CCR $5 \Delta 32 / \Delta 32$ mutation to this patient (recipient of bone marrow transplantation). After a successful bone marrow transplantation with mutated (CCR5 $\Delta 32 / \Delta 32)$ bone marrow, this patient did not show any signs for HIV positivity, even though anti-retroviral treatment was stopped for this patient (Hütter et al. 2009). Clinicians are hopeful that this patient may remain HIV-free, but still the concerns about the possibility for the activation of HIV from HIV reservoir do exist in this patient. The answer to this question or these questions has to wait simply for time.

Acknowledgments Authors are thankful to Mr. Dinesh Kumar, Amity University Uttar Pradesh (AUUP), Noida, for his excellent contribution to develop graphics for this book chapter. Mr. Abhijit Mukherjee is duly acknowledged for his excellent skills and contribution toward the word processing of the manuscript. Research scholars Ms. Ayushi Mishra and Ms. Riya Chaudhary working in the Biochemistry Dept. of BHU are acknowledged for proofreading the manuscript. The role of Ms. Dharashree Rout for the accessory services toward the completion of this manuscript is duly acknowledged.

\section{References}

Barre-Sinousi F, Chermann JC, Rey F, Nugeyre MT, Chamaret S, Gruest J, Dauget C, AxlerBlin C, Vezinet-Brun F, Rouzioux C, Rozenbaum W, Montagnier L (1983) Isolation of a T-Lymphotrophic retrovirus from a patient at risk for Acquired Immune Deficiency Syndrome. Science 220:868-871

Berger EA, Murphy PM, Farber JM (1999) Chemokine receptors as HIV-1 co-receptors: roles in viral entry, tropism, and disease. Annu Rev Immunol 17:657-700

Boehringer Ingelheim Pharmaceuticals Incorporated (2005) NNRTI mode of action (animation). www.boehringer-ingelheim.com 
Fenouillet E, Barbouche R, Courageot J, Miquelis R (2001) The catalytic activity of Protein Disulfide Isomerase is involved in Human Immunodeficiency Virus envelope-mediated membrane fusion after CD4 cell binding. J Infect Dis 183:744-752

Frankel AD, Young JA (1998) HIV-1: fifteen protein and an RNA. Annu Rev Biochem 67:1-25

Freed EO (2001) HIV-1 replication. Somat Cell Mol Genet 26:13-36

Gallo RC, Salahuddin SZ, Popovic M, Shearer GM, Kaplan M, Haynes BF, Palker TJ, Redfileld R, Oleske J, Safai B, White G, Foster P, Markham PD (1984) Frequent detection and isolation of cytopathic retroviruses (HTLV-III) from patients with AIDS and at risk for AIDS. Science 224:500-503

Gottlieb MS, Schroff R, Schanker HM, Weisman JD, Fan PT, Wolf RA, Saxon A (1981) Pneumocystis carinii pneumonia and mucosal candidiasis in previously healthy homosexual men: evidence of a new acquired cellular immunodeficiency. N Engl J Med 305:1425-1431

Hütter G, Nowak D, Mossner M, Ganepota S, Mubig A, Allers K, Schneider T, Hofmann J, Kücherer C, Blau O, Blau IW, Hofmann WK, Thiel E (2009) Long-term control of HIV by CCR5 delta32/delta32 Stem-cell transplantation. N Engl J Med 360:692-698

McArthur JC, Brew BJ, Nath A (2005) Neurological complications of HIV infection. Lancet Neurol 4:543-555

McCombe JA, Noorbakhsh F, Buchholz C, Trew M, Power C (2009) NeuroAIDS: a watershed for mental health and nervous system disorders. J Psychiatry Neurosci 34:83-85

Olender S, Wilkin TJ, Taylor BS, Hammer SM (2012) Advances in anti-retroviral therapy. Top Antivir Med 20:61-68

Olivier IS, Cacabelos R, Naidoo V (2018) Risk factors and pathogenesis of HIV-associated neurocognitive disorder: the role of host genetics. Int J Mol Sci 19(11):E3594

Peters PJ, Richards K, Clapham P (eds) (2013) Human immunodeficiency viruses: propogation, quantitation and storage. In: Current protocols in microbiology, vol 28. Wiley, Hoboken

Power C, Boisse L, Rourke S, John GM (2009) NeuroAIDS: an evolving epidemic. Can J Neurosci 36:285-295

Ryser HJP, Fluckiger R (2005) Progress in targeting HIV-1 entry. Drug Discov Today 10:1085-1094

Saag MS, Benson CA, Gandhi RT, Hoy JF, Landovitz RJ, Mugavero MJ, Sax PE, Smith DM, Thompson MA, Buchbinder SP, Del Rio C, Eron JJ Jr, Fätkenheuer G, Günthard HF, Molina JM, Jacobsen DM, Volberding PA (2018) Antiretroviral drugs for treatment and prevention of HIV infection in adults: 2018 recommendations of the international antiviral society-USA panel. JAMA 320(4):379-396

Tang MW, Shafer RW (2012) HIV-1 Antiretroviral resistance: scientific principles and clinical applications. Drug 80(71, 9):e1-e25

UNAIDS Report (2012) Report on the global AIDS epidemic

Verma AS, Singh UP, Dwivedi PD, Singh A (2010) Contribution of CNS cells in neuroAIDS. J Pharm Bioallied Sci 2:300-306

Verma AS, Singh UP, Mallick P, Dwivedi PD, Singh A (2012) NeuroAIDS and omics of HIV vpr. In: Barh D, Blum K, Madigan MA (eds) Omics biomedical perspectives and applications. CRC Press, Boca Raton, pp 477-511

Wilmshurst JM, Hammond CK, Donald K, Hoare J, Cohen K, Eley B (2018) NeuroAIDS in children. Handb Clin Neurol 152:99-116

Zhu T (ed) (2005) Method in molecular biology vol. 304: human retrovirus protocols: virology and molecular biology. Humana Press, Totowa, New Jersey.

\section{Further Reading}

Alfred M, Behrens G, Braun P and Bredeek UF (2011) HIV-2011. www.hivbook.com

Barnett T, Whiteside A (2006) AIDS in the twenty-first century: disease and globalization. Palgrave Macmillan, New York 
Lever AML (1996) The molecular biology of HIV/AIDS. Wiley, Hoboken

Levy JA (1998) HIV and the pathogenesis of AIDS. American Society for Microbiology, Washington, DC

Sax PE, Cohen CJ, Kuritzkes DR (2012) HIV essentials. Jones and Bartlett Learning, Burlington Stine G (2011) AIDS update 2012/ edition 21st. McGraw Hill Companies, Inc., New York

Weeks BS, Alcamo IE (2010) AIDS: the biological basis. Jones and Bartlett Learning, Burlington 